Revista Iberoamericana, Vol. LXXII, Núm. 215-216, Abril-Septiembre 2006, 325-336

\title{
LA POESÍA DE JUAN FELIPE TORUÑO: TRADICIÓN E INNOVACIÓN
}

POR

Yvette Aparicio

Juan Felipe Toruño se ha marchado. Sobre un lomo de fuego iba veloz

proclamando su ímpetu, su viaje y su inconformidad. de "Noticia", Raíz y sombra del futuro (1944)

Mis pies ya están cansados de trajinar sin rumbo. Sembraron ya mis manos demasiadas ortigas. Mi lengua ya no encuentra la palabra precisa que exprese lo que duelen las propias ansias mías... de "Elogio de la noche", Huésped de la noche (1947)

Juan Felipe Toruño, entre sus muchas actividades literarias y culturales, también escribió ocho colecciones de poesía. ${ }^{1}$ El hecho de que se dedicó al oficio de poeta se repite en comentarios sobre su obra, pero la poesía misma, con algunas excepciones periodísticas, no se ha discutido en detalle. ${ }^{2}$ Su famosa influencia en los medios culturales salvadoreños, particularmente a través de la dirección del suplemento cultural, Sábados de Diario Latino, y su papel como mentor de poetas jóvenes como los de la "Generación Comprometida”, ha sobrepasado el conocimiento de su posición como poeta. Por ejemplo, en su historia literaria de El Salvador, Panorama de la literatura salvadoreña, Luis Gallegos Valdés se refiere a Toruño repetidamente, pero siempre como crítico literario.

Es de notar que, en su Índice antológico de la poesía salvadoreña, David Escobar Galindo sí incluye su poesía. Algunos podrían decir que esta discrepancia se debe a un juicio de críticos salvadoreños sobre la nacionalidad del poeta. Pero aún en Nicaragua la poesía de Toruño no ha recibido suficiente atención. Por ejemplo, en su Diccionario de

${ }^{1}$ Juan Felipe Toruño publicó los siguientes poemarios: Senderos espirituales; Ritmos de vida; Hacia el sol; Vaso espiritual; Raíz y sombra del futuro; Arcilla mística; Huésped de la noche y Orbita de sonetos.

${ }^{2} \mathrm{Al}$ final de Huésped de la noche Toruño incluye una serie de comentarios, en su mayoría periodísticos, acerca de su obra poética (84-95). "Fragmentos de opiniones acerca de la obra poética y literaria de Juan Felipe Toruño", de Poemas andantes: ensayos sobre literatura europea y oriental también incluye una variedad de comentarios de la obra poética, narrativa y ensayística, y de la labor cultural de Toruño (9-33). 
escritores centroamericanos, Jorge Eduardo Arellano hace un comentario breve acerca de la poesía de Toruño; pero en su estudio conocido, Literatura nicaragüense, no discute su poesía aunque menciona su crítica literaria y obra narrativa. La pregunta que surge es, ¿por qué no hay estudios detallados de su poesía? Mas, la respuesta no está clara. Aunque tal vez se podría decir que por la productividad mayor de Toruño en otros géneros es fácil no examinar su poesía al discutir su obra narrativa y crítica.

La poesía de Toruño puede no aparentar grandes innovaciones en cuestiones de forma y de contenido. Pero al explorar su producción poética en diferentes etapas se perciben sus inquietudes y experimentación estéticas. En general, la poesía de Toruño es una poesía que apunta hacia ideas “universales”, o sea que en ella se manifiesta una conceptualización literaria convencional: el poema representa la “intuición que es una razón” y su producción es "sin razón” ("Expongo" 7). Tanto la importancia dada a la intuición e implícitamente aquí a la inspiración, como el deseo de representar el "pensamiento humano sublimado" sitúan esta poesía dentro de un entendimiento poético enraizado en tradiciones aceptadas como “poéticas” (“Expongo” 8). Las preocupaciones que Toruño expone en el prólogo de Hacia el sol (1940) tanto como en sus poemas, por ejemplo, el enamoramiento, la angustia vivencial, la soledad y la búsqueda por la verdad, claramente encaran temas de carácter “universal.” En términos de forma la poesía de Toruño comienza arraigada en el formalismo rubendariano para luego experimentar con el verso libre o más concretamente, como juzga Escobar Galindo, “Como poeta, surge modernista, y luego se esfuerza por asimilar sustancias vanguardistas" (306). Pero estas incursiones hacia "las formas extravagantes”, como el mismo Toruño describe el vanguardismo poético, no desvían el camino del poeta (Desarrollo literario ... 344).

La esperada influencia de Darío se extiende a su trabajo periodístico, pues funda y luego dirige la revista Darío hasta su partida de Nicaragua a El Salvador en 1923. A juicio de Rhina Toruño, en sus comentarios sobre el papel de Toruño en el desarrollo de la literatura salvadoreña, el establecimiento de esta revista fue motivado por el deseo de "continuar el discurso poético daríano" y de "no sólo entusiasmar sino apoyar a los jóvenes a incursionar en la poesía” (“Mesa redonda”). Pero en su propia exposición sobre Darío, Juan Felipe Toruño la describe como "centro de promociones e inquietudes. Se quería darle vuelta a la forma; pero el ambiente conservador de ritual emotivo, de canto y de grima, no lo permitía” (Poesía y poetas ... 273). La queja del estancamiento del ámbito poético leonés difiere sustancialmente del criterio de que la revista proponía alargar la influencia daríana. Pero pese a estas perspectivas diferentes sobre el significado de la revista, se llega a la misma conclusión acerca de la vía poética de Toruño: conciencia de tradición e innovación, y producción de poesía que muestra ambos llamados.

Toruño publica poemarios en los años veinte, cuarenta y cincuenta, años de innovación vanguardista y del comienzo de la politización contemporánea de la poesía. Las tendencias vanguardistas continentales hallan su expresión centroamericana en el país natal de Toruño, después de su salida a El Salvador en 1923. Como gran lector y crítico literario Toruño sabría de la combatividad estética, y por un tiempo política, de sus compatriotas granadinos. Y aunque en esa época la poesía salvadoreña no pervivió el mismo tipo de revolución formal, en los años treinta y cuarenta comenzó la integración de 
una política contundente que llegó a predominar en la poesía de ese país. En la poesía de Toruño se hallan ambas corrientes poéticas, la vanguardista y la política, junto a un conocimiento agudo de los valores poéticos aceptados por la tradición.

Para apreciar mejor la unión de estas corrientes en Toruño se hará un análisis poético comenzando con Hacia el sol (1940). Como se comentó anteriormente, el prólogo de este poemario enfatiza el papel de la espiritualidad del poeta en la creación del poema. "Hora”, poema dedicado a otro joven narrador nicaragüense, Ulises Terán, trata el futuro desconocido a la vez que reflexiona sobre la labor poética. Ambos temas pueden ser clasificados como "universales". Ostensiblemente el poema es un lamento de una voz poética que lucha por encontrarle significado a una vida que depende de una mañana que no se puede controlar. La primera estrofa introduce el lamento dolorido del hablante:

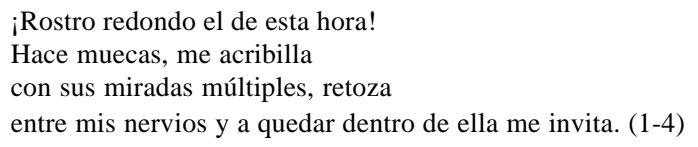

La personificación de la "hora”, con el énfasis en sus gesticulaciones y el efecto de éstas en el pobre yo, crea una relación de victimario y víctima que perdura a través de todo el poema. Nótese que la violencia de la hora es solamente gesticular y del mirar (2-3); pero pese a la sutileza de este ataque, el hablante se siente acribillado. ${ }^{3}$ Este sentimiento de dolor del hablante no se limita a la aceptación de vejaciones por parte de la "hora”, pues, él reside dentro de ella (4) y le entrega "esencias de [su] alma” (6). En el contexto en que la situación indigna del yo cambia es ante la "palabra”, él revela que "Se me entregó desnuda la difícil palabra” (13). La palabra poética, que en el prólogo a la colección es "íntima poesía liberada” (5), aquí es "poseída”, figurativamente en posición femenina, por un yo masculino. O sea que la entrega del yo en el verso sexto no es duradera, pues rápidamente éste se convierte en el poseedor de la “esencia” verbal de la palabra desnuda. La posesión lingüística del hablante, además de repetir los principios expuestos por Toruño al principio de este poemario, postula que es posible tener control sobre la intuición poética ("Expongo" 5-9).

El hablante de "Hora” no se nombra “poeta” pero la cuarta estrofa y la presentación en la sexta estrofa de sus “ansias misteriosas” aluden a la intuición e inspiración poéticas:

Estoy temblando con ansias misteriosas.

Siento que giran astros dentro de mi pensamiento;

oigo que hablan mil seres con frases insonoras

y veo llorar dioses hastiados de lo eterno. (21-24)

\footnotetext{
${ }^{3}$ En varias instancias en sus poemas amorosos los hablantes de Toruño presentan la relación en términos similares. Por ejemplo, véase "Pórtico" de Vaso espiritual: "Y tu mirada / La misma Mirada que persigue mis días y mis sueños y que me ve en / estos momentos enraizar mi desolación [. . .]" 52-54.
} 
Los temblores del hablante del verso 21 hacen de la poesía una experiencia “corporal”, no solamente mental o sentimental. Esta corporalidad es paralela a la de la “entrega” verbal de la cuarta estrofa. El hablante, que unas estrofas atrás se halla ante la mirada lastimadora de la hora y la desnudez de la palabra, aquí recibe golpes mentales de “frases insonoras” además de atestiguar el resultado de la eternidad, el hastío. El énfasis en las acciones de dar y recibir y en la concepción de la poesía sugiere que el hablante vive la labor poética activamente, tal vez sin hastiarse. También señala que esta labor lo abarca todo. Y el hastío experimentado por los dioses (24) no pertenece solamente a la eternidad sino que también a la vida del hablante:

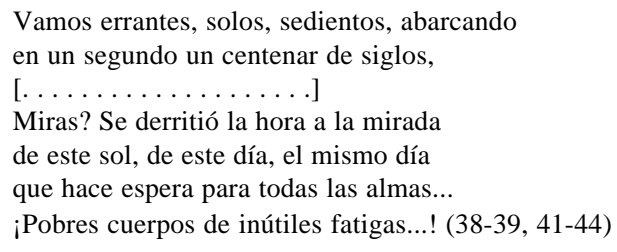

El hablante se da cuenta de la realidad del poder y la flaqueza (ante el sol) de la hora, o del tiempo, por tener la capacidad de escuchar girar "astros" en su mente y "frases insonoras” y de mirar a dioses llorosos. ${ }^{4}$ Se puede aseverar, entonces, que este hablante es el aludido del prólogo, aquél que experimenta la razón “sin razón” (7).

"Hora” por lo tanto sirve para presentar cómo habitan en el verso de Toruño las vanguardias, en la imagen "sorprendente” que produce la prosopopeya de la hora, y la tradición poética, en los temas universales y las convenciones de rima asonante. Ciertamente este poema fechado “Mayo 1925” muestra la innovación poética de la época de una manera leve. Pero esta levedad misma refuerza la aserción que en su poesía existe una tensión entre lo novedoso y la convención. Esta tensión, tal vez paradójicamente leve, también se encuentra en un poema engañosamente sencillo de Hacia el sol. "Con el misterio en la ilusión”, poema de verso libre, comienza hablando de una mascota dormida:

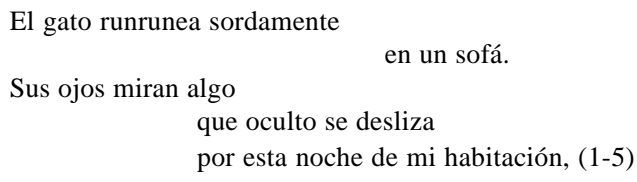

La descripción, casi jovial por el uso de la onomatopeya, es de un evento cotidiano y aparentemente trivial, pero sirve para fotografiar a un hablante (molesto) por la interrupción de su meditación: "He cerrado las puertas de mi libro / y quedo en la gruta

${ }^{4}$ También se debe anotar la importancia que "Expongo" le da al sol: "Podría este libro llamarse Hacia la Luz o Hacia la Verdad; pero siendo el sol representante de una jerarquía solar, universal, para dar una idea real, dí (sic) tal nombre a este volumen de poemas” (8). 
de la meditación” (8-9). Esta interrupción del pensamiento del yo le permite abrirse a otras meditaciones ya que le advierte que el silencio que percibe realmente no existe:

\author{
Estoy buscando el claro sentido del silencio; \\ pero las argollas de la hamaca \\ suenan tétricamente: \\ BRICK - BRACK... BRICK - BRACK. (29-32)
}

En estos versos la cotidianidad se entrepone entre el hablante y el "sentido del silencio" (29); la integración de objetos no-poéticos muestran la influencia de nuevas poesías. ${ }^{5}$ Y además la expresión onomatopéyica "BRICK-BRACK” de la hamaca alude a la frase "bric-à-brac" que denota un revoltijo de cosas. La utilización del sonido "BRICKBRACK,” llamativo en mayúsculas, apunta hacia la manipulación tipográfica de las vanguardias y representa simultáneamente todos los objetos que rodean y fascinan al hablante mientras medita.

A la vez que calladamente incluye técnicas “nuevas” el hablante, de manera similar a en "Hora," lamenta la realidad vivencial del poeta:

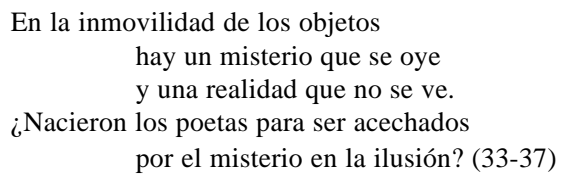

El acecho del que se queja el hablante aquí recuerda el acribillamiento de "Hora”. En ambos poemas el yo es víctima de violencia por su oficio de poeta: la habilidad perceptiva que le facilita la escritura de poesía también es un mal que lo hace reconocer que el pavor que le producen el "tic tac de los alientos rítmicos” (42) y el ruido siniestro de la hamaca (45) es por la incomprensión del alma: “El alma está radiante..., incomprendida!” (54). La búsqueda de respuestas a preguntas acerca del estado anímico humano es el rol aceptado del poeta, pero en el tratamiento de este "problema" humano, el hablante-poeta de "Con el misterio en la ilusión” sale de lo convencional para infundir lo cotidiano o lo trivial con el poder de despertar al poeta. Hay que notar que el gato que al principio interrumpe al poeta en su meditación permanece fuera del poema hasta el final cuando el hablante confirma la insignificancia del gato en su revelación:

$$
\begin{aligned}
& \text { El gato, indiferente, } \\
& \text { se ha dormido con tranquilidad. (56-57) }
\end{aligned}
$$

O sea que el "bric-à-brac” llega a representar la inspiración para un poema sobre “el misterio” del alma. Así, con esta técnica el poema cabe dentro de la tradición vanguardista.

\footnotetext{
${ }^{5}$ Este poema está fechado “León, Nicaragua, 1939”.
} 
Al significado que este poema les da a los objetos de la vida diaria, incluyendo la mascota, se le puede ver otra cara en la inclusión de la política. Esta faceta de la poética de Toruño se encuentra en Hacia el sol en “Mensaje a los hombres de América” donde el hablante les suplica a los americanos:

... Escuchad!

A vosotros os hablo constituidos en guión que se extiende]

entre la cultura de hoy y la cultura del mañana!

(13-15)

El poema presenta a "los hombres americanos" como posibles salvadores de un mundo que:

\author{
[...] entre ígneas tormentas envenénase. \\ Estalla en famélicos odios. \\ Caínes, modernos, Brutos sanguinarios, asesinan, traicionan.] (1-3)
}

El fuerte lenguaje con el cual el hablante describe a los contrincantes le hace eco al famoso poema dariano “A Roosevelt” y a otro verso del mismo Toruño que trata de la intervención estadounidense en Nicaragua, "Y un soldado yanqui vestido de pus pasa". ${ }^{6}$ La exhortación americanista de este poema luego se ensancha en el poemario publicado en 1944, Raíz y sombra del futuro. ${ }^{7}$

Comenzando con el epígrafe de Toruño que abre Raíz y sombra del futuro, este poemario funciona como una imputación poética de la condición actual del mundo y un llamado al continente a que éste actúe para mejorar el mundo. El epígrafe de Toruño establece las pautas temáticas del volumen además de definir explícitamente su papel sociopolítico como Poeta:

\footnotetext{
Unos hacen la guerra. Otros pelean y mueren en ella. Otros sacan provecho de ella. Otros fabrican tanques, bombas, cañones que destruyen vidas y ciudades. Yo siento esa guerra. Hago poesía. Naufrago en el alma de la sangre de tanta herida y muerte y me embarco al futuro en una lágrima. (El énfasis es mío.)
}

\footnotetext{
${ }^{6}$ Toruño cita y explica este verso en su auto-descripción en Poesía y poetas de América (273). Cuando discute poesía anti-yanqui, Arellano también cita este verso, denominándolo de "repugnancia” y "de filiación rubendariana” (Literatura nicaragüense 57). En este verso también se nota la filiación con el epigrama XVIII más tardío de Cardenal, "Es Somoza que pasa”.

${ }^{7}$ Es interesante que "Mensaje a los hombres americanos" esté incluido otra vez en esta colección. Por su tema americanista y político su integración en Raíz y sombra del futuro es lógica y fácil de comprender.
} 
El establecimiento de sí mismo como poeta que siente y lamenta los hechos mundiales, como la Segunda Guerra Mundial, no difiere sustancialmente de las aserciones hechas años atrás en “Expongo,” el prólogo de Hacia el sol (1940). Las diferencias entre ésta y aquella exposición residen en el lenguaje y el contexto. Por ejemplo, "Expongo” no sitúa al expositor en un ámbito específico sino que lo conecta a concepciones poéticas universalmente aceptadas como tales. ${ }^{8}$ En este epígrafe, que funciona como prólogo, inserta imágenes (tanques, bombas, cañones) y menciona hechos ("esa guerra”) que corresponden a la realidad histórica en que vive. Éste es un cambio significante si se toma en cuenta la politización que experimenta la poesía del istmo. En este epígrafe Toruño muestra una corriente que dominará la literatura durante décadas. ${ }^{9}$ Pero este poeta, a diferencia de los jóvenes poetas a quienes ayudará en los años sesenta y setenta, no aboga por cambios radicales ni defiende el martirio político, sino que incursiona en la política para exigir el derecho de vivir en paz. La selección del demostrativo “esa” para referirse a la guerra hace hincapié en su distancia de los hechos. Se puede decir que esta distancia no se explica sólo por la distancia física entre Centroamérica y los centros guerreros, sino también por el foco de su posición ante la guerra como poeta, lo que también apunta a su lejanía.

O sea que su política-poética no entra en $\operatorname{dogmas}^{10}$ ni polémicas, pues es un grito de afirmación vivencial, como dice el primer poema, "Santo y seña":

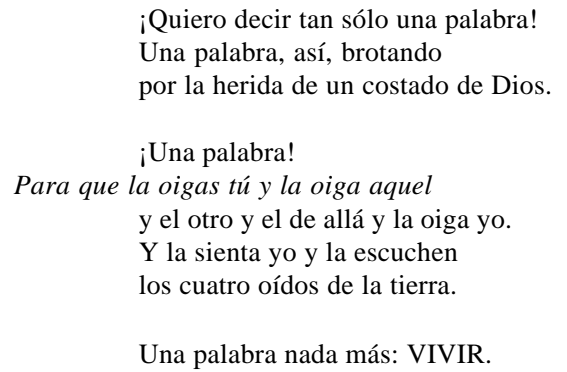

Aquí la lucha del hablante poético es solamente por "los cuatro oídos de la tierra” y su mensaje pacífico es sencillo de comprender. Busca un valor "humano”; no habría

\footnotetext{
${ }^{8}$ En contraste, en el prólogo de Ritmos de vida, Toruño menciona su ambiente contextual para extraerse a sí mismo y a su poesía. En otras palabras, allí intenta mostrar la incongruencia entre su arte y su mundo actual: "Mi poesía, mi modo lírico, objetivo, sugestivo, o subjetivo, vibra en mi ser (sic) como una cosa viva: [...] Nieto de España, de no haber nacido en León de Nicaragua sería un francés de medio siglo diecinueve" (6).

9 Recordar, por ejemplo, a Pedro Geoffroy Rivas, el Grupo seis y la Generación Comprometida.

${ }^{10}$ El desafecto de Toruño hacia los dogmas en la poesía se dilucida en comentarios acerca de la Generación Comprometida: "Quisieran que todo estuviese bajo el imperio de sus principios y actitudes, a manera de monopolio del conocimiento sin conocimiento. Lo que no está con ellos está contra ellos [...] Y como no logran lo que quieren, se lanzan inútil y afanosamente contra los mayores. Una manera dogmática per se, demagógica, tornando en política lo que debería ser realización de ideal” (Desarrollo literario de El Salvador 427).
} 
manera de oponerse realmente al deseo de este hablante. No lucha por ningún partido, ni causa ni resultado específico. ${ }^{11} \mathrm{Y}$ aunque su sencillez formal y de contenido responde a las exigencias de una poesía política, la vaguedad de ese contenido lo diferencia de lo que se producirá posteriormente en este género de poesía. ${ }^{12}$

Otros poemas más extensos de esta colección comparten con "Santo y seña" sentimientos de reproche y de solidaridad humana un tanto abstractos. En "Llamado con voz de América", por ejemplo, el hablante de Toruño une dos aspectos "políticos" diferentes: el americanismo (aquí representado por la bondad, riqueza y civilización americana) y la solidaridad con los pueblos europeos sufrientes por la guerra. Fundamentalmente, este poema relata la historia dolorosa de América, “¡Triste ha sido la América!” (31), y reitera su papel protector en el mundo actual, “Aquí está el fogón dispuesto para cuerpos ateridos / y está la sombra extensa y protectora” (11-12). Lo que añade a lo ya visto en "Mensaje a los hombres de América” es un tono irónico.

Mientras que en el poema anterior el hablante exalta los bienes de América e intenta instigar acción por parte del receptor, en éste el yo presenta a América y a los sufridos de una manera más crítica. En “Mensaje a los hombre de América” la descendencia indígena de los americanos es vista como símbolo de grandeza futura; y la guerra europea, que es "tragedia bárbara”, es contrapuesta a aquel futuro (18). Por otra parte, en "Llamado con voz de América” hay una conciencia clara de la percepción mundial de América y ésta no coincide necesariamente con la de un pueblo que pueda salvar o proteger al mundo:

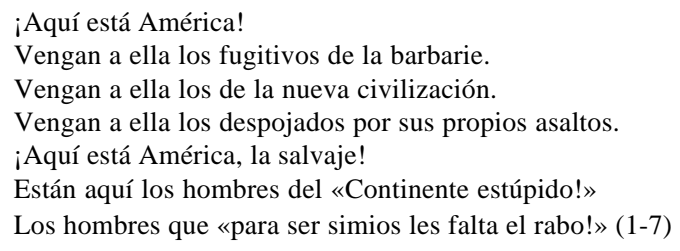

En esta estrofa el hablante establece varias facetas importantes del poema. Contrapone su contexto, América, al de "ellos”. El yo invita a su mundo a aquéllos de la "nueva civilización" que irónicamente sufren de la "barbarie” de "sus propios asaltos" (2-4, 7276, 98-102). Hay una crítica solapada de "los despojados", a los que se les ofrece refugio, por ser culpables de su situación. Sorprendentemente, para la poética de Toruño, el hablante repite opiniones muy pesadas y sarcásticas de su querida América en los versos

\footnotetext{
${ }^{11}$ Es importante mencionar que en su juventud Toruño participó en la lucha armada liberal en contra de la invasión estadounidense de Nicaragua de 1912 (Diccionario de escritores centroamericanos 109). Además, en el diario nicaragüense La nueva prensa, Ramiro Córdoba, en 1950, alaba "la sinceridad” de las descripciones de las montañas de Toruño en su novela El silencio (1935). Dice que ésta se debe al hecho de que el autor "Fue soldado en las revoluciones y en las guerrillas nicaragüenses" (citado en "Fragmentos de opiniones acerca de la obra poética y literaria de Juan Felipe Toruño" de Poemas andantes 21).

${ }^{12}$ Ver ensayos de Ernesto Cardenal y Roque Dalton acerca de la escritura de poesía y la política, donde la posición ideológica y la participación política de sus autores son centrales a la discusión.
} 
seis y siete. Ahora bien, la utilización de comillas para resaltar el hecho de que estas enunciaciones vienen de otros le permiten al hablante distanciarse de éstas con un guiño de ojo y a la vez burlarse del "continente estúpido”. Los pueblos que ayer le proveyeron oro a los reinos colonizadores "también hoy da[n] su pecho al mundo" (15-16). Esta dádiva del mundo americano es apreciada o admirada por el hablante aunque éste se da cuenta del sacrificio que significa para América (22-26, 31-36). La oferta benévola del yo convierte la condición de víctima colonizada de América en la de "refugio para toda amargura, lumbre para toda oscuridad” (107) que perdona los “oprobios” ajenos que no logra reconocer (104-105).

La ignorancia americana en estos versos, a diferencia de los de la primera estrofa, deben hacer de ella una conquistadora "bienhechora" que acepta el trabajo de transformar a sus antiguos amos y de enseñarles cómo vivir en paz (108-114). A primera vista el énfasis en la realidad pacífica del continente al final del poema, "lección de paz, creación de paz, trabajo en paz”, parece ser un regreso a la visión de mundo de "Santo y seña”, pero el poema no termina allí (113). El último verso, repetición casi exacta de los versos 43 y 44 , “en el pecho donde Colón lactó su eternidad”, no deja olvidar la triste historia americana (114). La América que el hablante le ofrece a "la tragedia de hoy" (102) permanece siendo el continente de "simios" de la primera estrofa que regalará su oro porque es el eterno aposento de Colón. El tono irónico del yo cuestiona la aceptación americana de su destino de protectora y de riqueza para otros. El hablante se alegra del rol salvador a la vez que lo cuestiona sutilmente por medio de su tono. ${ }^{13}$

La inclusión de esta figura retórica amplía el mensaje político del poema y conecta la poética de Toruño a sus contemporáneos que también la utilizan en su crítica. Esta incursión a la crítica social, un campo no siempre aceptado como válido para la poesía, no se apodera de la obra de Toruño como lo hace otros poetas. En un poemario de pocos años más tarde, Huésped de la noche, los hablantes poéticos de Toruño se alejan de la contextualización histórica y política de Raíz y sombra del futuro. Para el yo de esta colección de 1947, el sol brillante de Hacia el sol y la "ciudad futura” americana de Raíz y sombra del futuro se han desvanecido para revelar el poder de la sombra en su vida: “ ¡Y la sombra es!" ("Huésped de la noche” 38). El sentimiento de angustia que agobia al hablante de Huésped de la noche recuerda los poemarios anteriores donde el yo se lamenta su acribillamiento por fuerzas inexplicables. La experiencia del dolor vivencial humano de cierta manera abstracta vuelve fuertemente en estos poemas.

Este poemario es una vuelta a preocupaciones propias de la poesía; en el poema titular, por ejemplo, el yo se ve a sí mismo como "huésped” de la noche llena de ecos:

$$
\begin{aligned}
& \text { ¡El eco sigue...! } \\
& \text { La noche está poblada de ecos. }
\end{aligned}
$$

\footnotetext{
${ }^{13}$ Hay que resaltar el hecho de que la fecha de publicación de "Llamado en voz de América” (1944) es un año de intensa acción política popular en El Salvador en contra del Presidente General Maximiliano Hernández Martínez y el año de su caída del poder. En Nicaragua en cambio, Anastasio Somoza García continuaba consolidando su poder pese al descontento de la población. Por lo tanto, la afirmación poética de paz en estos momentos podría entenderse como una extensión del tono irónico del poema.
} 
El eco. Mi eco. Tu eco.

Nuestros ecos. (1-4)

Los alrededores del yo, los ecos, parecen estar acosándolo, o acusándolo, y él aparentemente no tiene salida. Estos primeros versos asientan el ambiente un tanto espectral del poema; este ambiente le presta profundidad a un poema que temáticamente es similar a poemas menos cargados como "Hora". En este poema el lector se pregunta ¿Cómo podría el yo escaparse de un sonido? La sangría así como los puntos suspensivos del primer verso presentan el poema como interrupción o continuación de una realidad establecida. La realidad de este yo poético es la repetición de ecos y el hecho de encontrarse torturado porque todos nosotros solamente "Somos el eco de una palabra dicha / en un día sin tiempos anteriores” (5-6). Su dolor es existencial pues no se es una totalidad individual sino la copia de una enunciación. Y a la vez este dolor es “poético” porque el yo sigue reoyendo lo producido anteriormente. La originalidad, tanto del ser individual como de la escritura, no es posible en este entorno. De tal manera el eco que lo atormenta es una afrenta a su persona y a su arte.

La existencia del hablante en este ambiente misterioso parece aún peor al considerarse su posición de "huésped de la noche”. La ambigüedad misma del vocablo que nombra el poemario y este poema los abre a diferentes interpretaciones. Si se comprende "huésped" como visitante, el poema funciona como representación del sufrimiento que le trae la noche al hablante. Y la primera mención en el poema del "huésped”, presenta la situación del yo poético así:

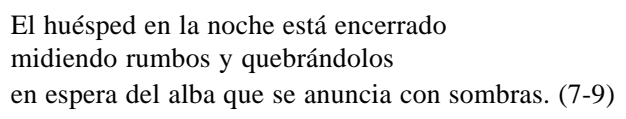

Si el yo es el huésped en la noche que espera que llegue el día, resulta ser una víctima cuya alma es agarrada por "desconocidos himnos" (13). El alma sufriente no puede deshacerse de los ecos ni hacer más que esperar el día (17-18). Este huésped "en su hospedaje de años" (16) busca a otros "habitantes" (19-20) de la noche pero solamente encuentra "milenarias voces" (26) que no le ayudan a "traspasa[r] la noche de su carne”(29). La oscuridad que está dentro del yo, hasta este momento en el poema, lo hace vagar por la noche mientras los ecos lo muerden y lo destrozan (42-43).

Pero en la siguiente y última estrofa, el eco o la repetición de los versos cinco y seis conducen al lector a otro significado de "huésped” y por lo tanto a otras posibilidades interpretativas del poema:

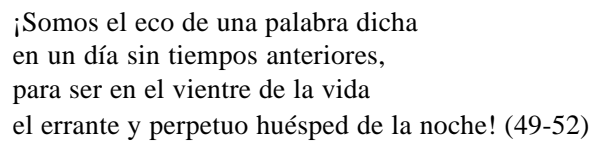

En contraste a la segunda estrofa donde el huésped reside en la noche, en estos versos el “nosotros” está dentro del “vientre de la vida” $(7,51)$. Además, hay una inversión de 
papeles entre la noche y el yo o nosotros, pues la noche se convierte en habitante de "nosotros.” Anteriormente, el poema había establecido los parámetros de la existencia del yo: vagar por "la noche de los ecos" (31). Pero por la flexibilidad significativa de "huésped” y la sintaxis de los versos, la noche deja de ser anfitriona y se transforma en visitante del yo-anfitrión. La transformación de la noche en "víctima”, por su encierro, hace del dolor del yo una construcción propia. La oscuridad literal y figurativa de la cual se queja el hablante en el resto del poema se revela al final como resultado de acciones de éste. En otras palabras, los últimos dos versos culpan al yo por su condición lamentable. La continuación del eco atormentador refleja la inhabilidad humana de deshacerse de la oscuridad. Esta conclusión reitera el juicio que se hace de las víctimas de guerra en Raíz y sombra del futuro. Parece repetir, en un contexto diferente, la exhortación de "Mensaje a los hombres de América”: “responsabilicémonos” (42). Con esta proclamación implícita al final, "Huésped de la noche" une ciertas preocupaciones de Toruño, como la solidaridad crítica y la universalidad de la angustia, en un poema en verso libre abierto a diversas interpretaciones. Deja atrás pronunciamientos contundentes y revela la complejidad de la angustia. $^{14}$

Estos análisis poéticos de la obra de Toruño muestran tanto su experimentación técnica y temática (la crítica social) como su exploración de temas convencionalmente poéticos(el amor y el dolor). A través de diferentes momentos históricos y colecciones de poemas se ve una tensión en hablantes poéticos aliados ambos a la tradición y a la innovación poética. Claro está que en su poesía Toruño muestra que pudo “[...] concluir de pie, fundido, encenizado. / Vertical en el canto” (“Acento” 17-18).

\section{BiBLIOgRAFÍA}

Arellano, Jorge Eduardo. Diccionario de escritores centroamericanos. Managua: ASDIBibliotecas Nacionales de Centroamérica y Panamá, 1997.

Literatura nicaragüense. 6 a ed. Managua: Ediciones Distribuidora Cultural, 1997.

Escobar Galindo, David. Índice antológico de la poesía salvadoreña. $2^{\mathrm{a}}$ ed. San Salvador: UCA Editores, 1987.

Gallegos Valdés, Luis. Panorama de la literatura salvadoreña. $3^{\mathrm{a}}$ ed. San Salvador: UCA Editores, 1989.

Toruño, Juan Felipe. Desarrollo literario de El Salvador. San Salvador: Ministerio de Cultura, 1957.

Orbita de sonetos. San Salvador: Imprenta Acosta, 1952.

Huésped de la noche. San Salvador: Imprenta Fúnes, 1947.

Arcilla mística. San Salvador: Imprimió J.T, 1946.

Poesía y poetas de América: Trayectos en ámbitos, fisonomías y posiciones. San

Salvador: Imprenta Fúnes, 1945.

Vaso espiritual. San Salvador: Imprenta Fúnes, 1941.

Hacia el sol. San Salvador: Imprenta Fúnes, 1940.

\footnotetext{
${ }^{14}$ Este poemario también incluye poemas que explícitamente piden la muerte, dejando atrás el
} miedo. Ver, por ejemplo, “Urgente” y “Acento.” 
Ritmos de vida. San Salvador: Centro Editorial Salvadoreño,1924.

Senderos espirituales. León, Nicaragua: Imprenta Los Hechos, 1922.

"Fragmentos de opiniones acerca de la obra poética y literaria de Juan Felipe Toruño". Poemas andantes: ensayos sobre literatura europea y oriental. San Salvador: Editorial Universitaria, 1977. 84-95.

“Expongo”. Hacia el sol. San Salvador: Imprenta Fúnes, 1940. 7.

Toruño, Rhina. "Mesa redonda: Juan Felipe Toruño como figura histórica en el desarrollo de la literatura salvadoreña”. Congreso internacional de historia, Universidad de El Salvador (San Salvador, 18-21 julio 2000). 